$\begin{array}{llll}\text { SUSANA BRÁS, MD } & \text { ANDRÉ OLIVEIRA, MD } & \text { PEDRO MENDES-BASTOS, MD } & \text { CRISTINA AMARO, MD } \\ \begin{array}{l}\text { Department of Dermatology, } \\ \text { Centro Hospitalar de Lisboa Central, } \\ \text { Lisbon, Portugal }\end{array} & \begin{array}{l}\text { Department of Dermatology, } \\ \text { Centro Hospitalar de Lisboa Central, } \\ \text { Lisbon, Portugal }\end{array} & \begin{array}{l}\text { Dermatology Center } \\ \text { Hospital CUF Descobertas, }\end{array} & \text { Dermatology Center, } \\ \text { Hospital CUF Descobertas, } & \text { Lisbon, Portugal } & \text { Lisbon, Portugal }\end{array}$

\title{
A dermatosis of pregnancy
}

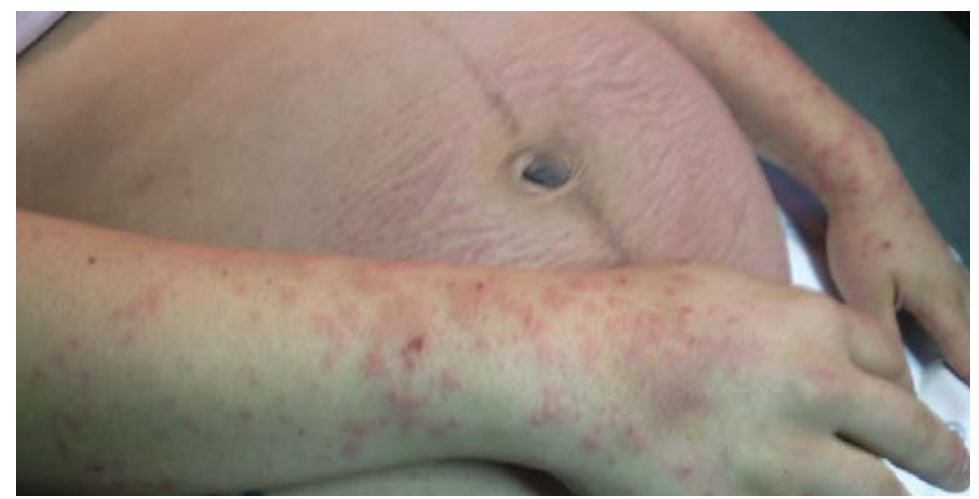

FIGURE 1. Erythematous papules and plaques on the upper limbs and in the lower abdominal striae, sparing the umbilical region.

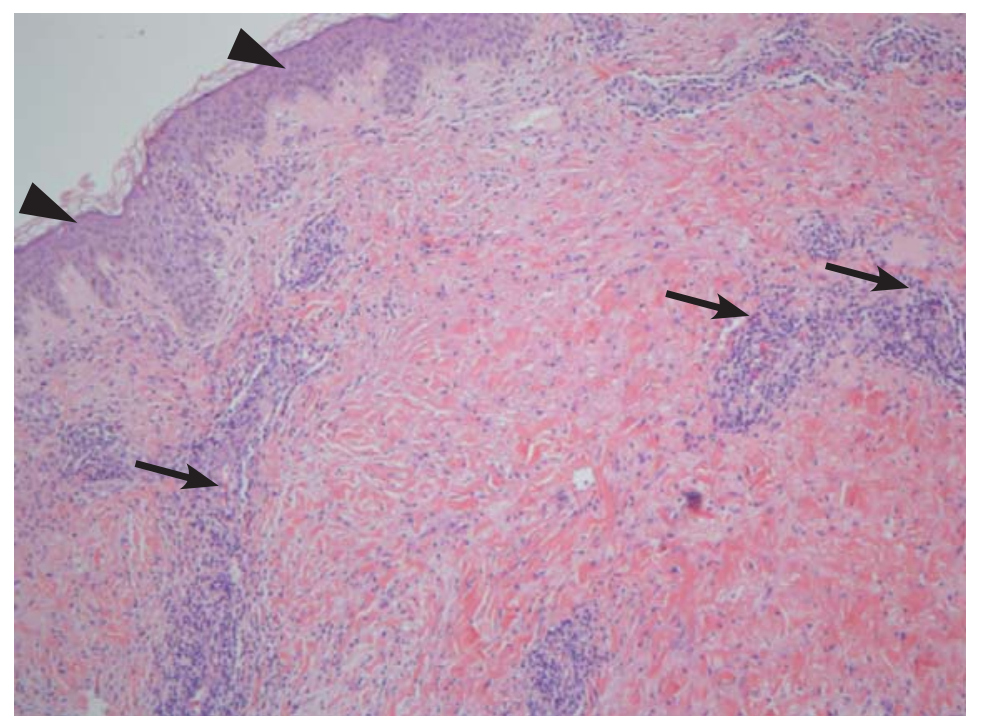

FIGURE 2. Histologic study of the abdominal plaque showed moderate superficial perivascular lymphohistiocytic infiltrate with eosinophils (arrows). Epidermal cells (arrowheads) appeared normal (hematoxylin and eosin, $\times 10)$.
N THE EIGHTH DAY AFTER giving birth to monochorionic twins, a 33-year-old woman presented with pruritic erythematous papules and plaques that started on the striae of the lower abdomen and spread rapidly to the thighs and upper limbs, sparing the umbilical region (Figure 1). Histologic examination of a specimen of the abdominal plaques showed moderate superficial perivascular lymphohistiocytic infiltrate with eosinophils (Figure 2), leading to the diagnosis of polymorphic eruption of pregnancy. Oral cetirizine $10 \mathrm{mg} /$ day and topical methylprednisolone cream brought complete regression of the lesions within 1 month.

\section{DERMATOSES OF PREGNANCY}

Polymorphic eruption of pregnancy-also known as pruritic urticarial papules and plaques of pregnancy ${ }^{1}$ - is a specific dermatosis of pregnancy characterized by pruritic urticarial papules on abdominal striae that usually first appear during the latter portion of the third trimester or immediately postpartum. It is more frequent in primiparous women and does not represent a risk to the mother or fetus. $^{2-4}$

The lesions tend to coalesce into plaques, spreading to the buttocks and proximal thighs. They then become more polymorphic and vesicular, with widespread nonurticated erythema and targetoid and eczematous lesions. Characteristically, the lesions spare the umbilical region. Their location within striae suggests that stretching of abdominal skin may damage the connective tissue, initiating an immune response with subsequent appearance of the eruption. ${ }^{2,4}$

The diagnosis is mainly clinical. In some cases, skin biopsy can help to confirm 


\section{TABLE 1}

\section{Clinical presentation of dermatoses of pregnancy}

\author{
Dermatosis \\ Pemphigoid gestationis \\ Polymorphic eruption \\ of pregnancy

\section{Atopic eruption of pregnancy (AEP)}

\section{Intrahepatic cholestasis of pregnancy}

Presentation

Erythematous urticarial papules and plaques that progress to tense blisters typically involving the umbilical region but may generalize

Pruritic urticarial papules and plaques on abdominal striae that generalize and become polymorphic; sparing of the umbilical region is a characteristic finding

Pruritic eczematous lesions affecting typical atopic sites such as face, neck, and flexural surfaces (AEP type E); or presence of papules and prurigo nodules disseminated on trunk and limbs (AEP type P); or follicular papules and pustules on trunk (pruritic folliculitis of pregnancy)

Generalized pruritus without primary skin lesions; secondary skin lesions develop from scratching; jaundice may occur the diagnosis. Histologic features are nonspecific and vary with the stage of disease, showing a superficial to mid-dermal perivascular lymphohistiocytic infiltrate with eosinophils. At earlier stages, biopsy results can show a prominent dermal edema.
In later stages, epidermal changes such as spongiosis, hyperkeratosis, and parakeratosis can occur. ${ }^{2}$

As an aid to diagnosis, Table 1 lists clinical differences between various dermatoses of pregnancy.

\section{REFERENCES}

1. Lawley TJ, Hertz KC, Wade TR, Ackerman AB, Katz SI. Pruritic urticarial papules and plaques of pregnancy. JAMA 1979; 241:1696-1699.

2. Ambros-Rudolph CM. Dermatoses of pregnancy-clues to diagnosis, fetal risk and therapy. Ann Dermatol 2011; 23:265-275.

3. Rudolph C, Shornick J. Pregnancy dermatoses. In: Bolognia JL, Jorizzo JL, Schaffer JV, eds. Dermatology. 3rd ed. London, UK: Saunders; 2012:441-443.

4. Rudolph CM, Al-Fares S, Vaughan-Jones SA, Müllegger RR, Kerl H, Black MM. Polymorphic eruption of pregnancy: clinicopathology and potential trigger factors in 181 patients. Br J Dermatol 2006; 154:54-60.

ADDRESS: Susana Brás, MD, Department of Dermatology, Centro Hospitalar de Lisboa Central, Alameda de Santo António dos Capuchos, 1169-050 Lisbon, Portugal; bras.susana@gmail.com

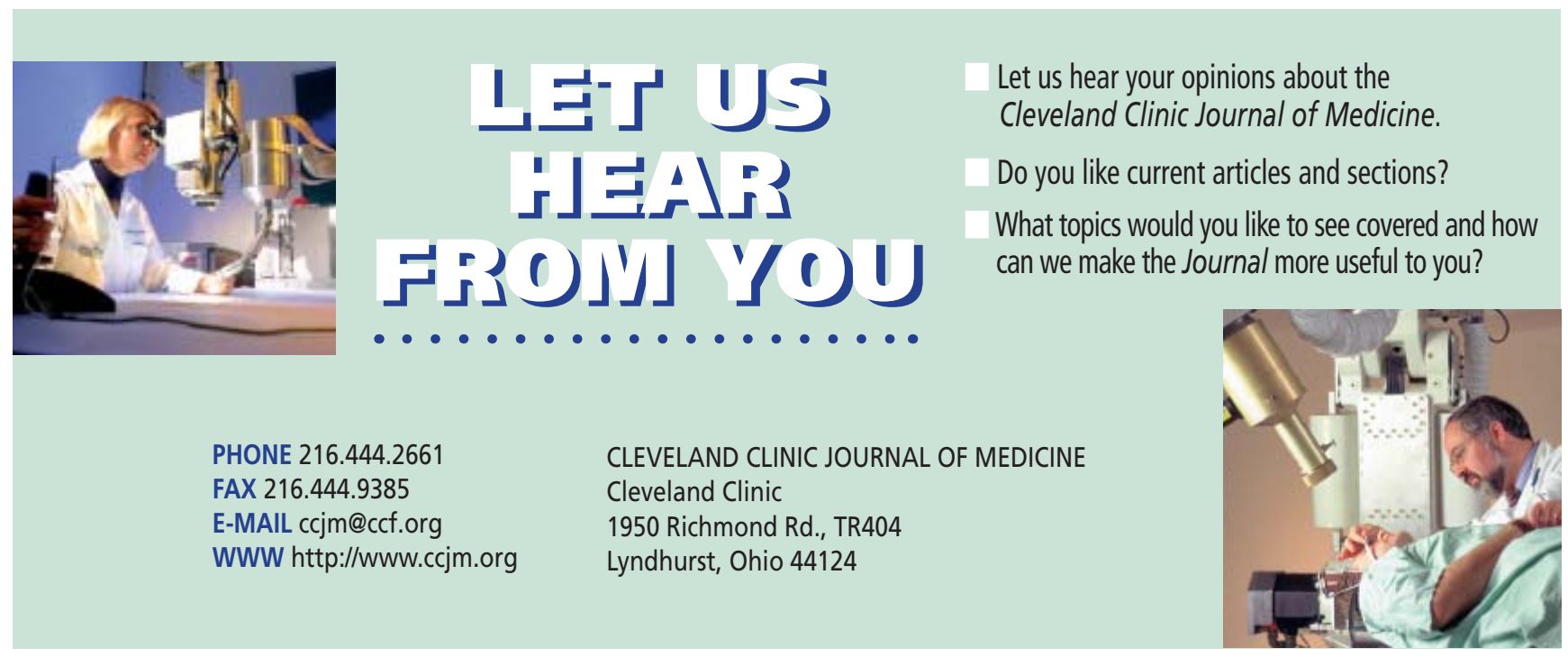

